\title{
EchoGéo
}

12 | 2010

La rue en Asie

\section{Los intereses sectoriales de la vivienda social en} Cuba

Tecnología vs. Diseño

\section{Adriana Rabinovich}

\section{(2) OpenEdition}

Journals

\section{Édition électronique}

URL : https://journals.openedition.org/echogeo/11695

DOI : 10.4000/echogeo.11695

ISSN : 1963-1197

\section{Éditeur}

Pôle de recherche pour l'organisation et la diffusion de l'information géographique (CNRS UMR 8586)

\section{Référence électronique}

Adriana Rabinovich, "Los intereses sectoriales de la vivienda social en Cuba », EchoGéo [En ligne], 12 | 2010, mis en ligne le 31 mai 2010, consulté le 31 juillet 2021. URL : http://journals.openedition.org/ echogeo/11695; DOI : https://doi.org/10.4000/echogeo.11695

Ce document a été généré automatiquement le 31 juillet 2021.

EchoGéo est mis à disposition selon les termes de la licence Creative Commons Attribution - Pas d'Utilisation Commerciale - Pas de Modification 4.0 International (CC BY-NC-ND) 


\title{
Los intereses sectoriales de la vivienda social en Cuba
}

\author{
Tecnología vs. Diseño
}

Adriana Rabinovich

1 En términos de tipologías y de modelos, la búsqueda de respuestas a la problemática de la vivienda social se encuentra atravesada por una tensión entre abordajes tecnocráticos -rápida y alta productividad a bajo costo- y enfoques de "diseño"-calidad estética y espacial relacionada con valores culturales.

2 Cuba no escapa a esta realidad. Y en tanto el debate de los primeros años de la revolución dio lugar a experiencias articuladoras de ambos abordajes, un recorrido por la isla basta para comprender que la política pública habitacional cubana implementada durante más de medio siglo, se tradujo en la producción masiva de viviendas colectivas de alta uniformidad y tipificación, implantadas en espacios anónimos, sin pretensión estética, elaboradas además sin vinculación entre proyectistas y futuros habitantes.

3 Paralelamente a la implementación de dicha política se desarrollaron estrategias de auto construcción a cargo de los habitantes mismos, quienes han ido manteniendo y mejorando el parque habitacional existente. Estas acciones se realizan en el marco de iniciativas individuales, generalmente sin asistencia técnica o de proyecto, por lo que frecuentemente presentan problemas de seguridad y de salubridad alarmantes. El potencial de construcción de la población fue también canalizado, aunque de manera organizada y con procesos de capacitación técnica, en los conocidos sistemas de ayuda mutua y de microbrigadas.

4 La interrupción de programas públicos de vivienda durante el "periodo especial" en la década de los 90, marcado por la ruptura de los lazos de colaboración económica que Cuba mantenía con los países del bloque del este, abrió la vía a acciones colectivas con diferentes grados de autonomía respecto del Estado. En el marco de la problemática del hábitat, las mismas defendieron la necesidad de innovar en la búsqueda de tipologías y modelos de vivienda, re-centrando el debate sobre la importancia de articular las dimensiones técnicas y las del diseño, y propusieron al mismo tiempo alternativas 
concretas de colaboración entre profesionales y habitantes, a través de experiencias "participativas".

5 La presente contribución analiza, desde una perspectiva histórica, los modos en que se fueron resolviendo las tensiones entre técnica y diseño en las políticas habitacionales cubanas, como también el rol atribuido a la población desde 1959, año de la revolución cubana. Pondremos en evidencia la predominancia de los enfoques tecnocráticos, sectorializados, desvinculados de los habitantes y por ende, la fragilidad de las experiencias innovadoras que durante la década de los 90 intentaron reconciliar dichos enfoques. Nos apoyaremos particular en las acciones implementadas por Hábitat-Cuba, Sociedad para la vivienda y el urbanismo, entre 1994 y $2001{ }^{1}$.

\section{Las fases de la política habitacional revolucionaria}

Durante los primeros años de la revolución cubana, el Estado declaró su responsabilidad total en relación con la problemática del hábitat, asumiendo en particular "la obligación de resolver el problema de la vivienda como una necesidad fundamental de los ciudadanos"2.

7 La situación heredada era de extrema gravedad. En 1958, sobre el total de viviendas existentes, cerca de la mitad eran consideradas de edificación inapropiada. En las zonas rurales, el $63 \%$ tenia suelos de tierra, el $91 \%$ carecía de alumbrado eléctrico y el $97 \%$ calificaba como viviendas en mal estado (Pleyán, Pérez, 2002). Tres objetivos principales marcaron el inicio de la política revolucionaria entre 1959 y 1961: la transformación radical del régimen de propiedad y del valor del suelo a través de diferentes medidas legislativas; la impulsión de la planificación territorial para la restructuración integral del territorio a través de las reformas agraria y urbana ${ }^{3} ; \mathrm{y}$ finalmente, la puesta en marcha de planes y proyectos de vivienda como bien social accesible a todos los sectores de la población. Diferentes fases resumen la concreción de dichos objetivos, tal como las describe Segre (1989).

\section{Políticas públicas y sector privado}

8 Las primeras acciones tendientes a garantizar el acceso a una vivienda digna, en particular para los sectores desfavorecidos de la población cubana, se centraron en el diseño e implementación de políticas sociales. Por un lado, se procedió a la redistribución de viviendas existentes vacías o abandonadas por la burguesía que emigraba de la isla, transfiriendo la propiedad de las mismas al Estado. Por otro lado y ante todo, la política habitacional se centró en la construcción de viviendas nuevas para cubrir las carencias del fondo existente y erradicar viviendas y barrios precarios e insalubres relocalizando a la población.

9 A nivel institucional, se crearon organismos como el Instituto Nacional de Ahorro y de Vivienda (INAV, 1959) el cual, con recursos provenientes de la Renta de la Lotería Nacional permitiría "reconvertir la negativa tradición del juego en formas de ahorro" para financiar la producción elevada de viviendas en corto plazo. Estos recursos financieros permitieron al Estado disponer de liquidez monetaria para adquirir materiales e infraestructuras, y pagar a contratistas privados que ejecutaban las obras. En 1960 se creó la Dirección de Investigaciones Técnicas en el Ministerio de Obras Publicas que orientó el estudio y la racionalización de técnicas y materiales. Poco 
tiempo después se crearon la Dirección de Viviendas Urbanas del Ministerio de Obras Publicas y la Dirección de Viviendas Campesinas (DVC) anexa al Instituto Nacional de Reforma Agraria (INRA).

10 En términos de producción entre 1959 y 1963, si bien no existía una estructura centralizada, el INAV estableció orientaciones y normas para conjugar los estándares de viviendas económicas artesanales en manos de empresas contratistas privadas y trabajadores autónomos, junto con la producción de viviendas por las empresas del Estado. Las $85^{\prime} 000$ viviendas urbanas construidas en este período responden a una amplia diversidad de soluciones tipológicas y dimensionales. Dos tercios fueron producidos por el estado en un proceso que en sus inicios incluyó la participación de los habitantes a través del sistema de esfuerzo propio -en el proceso de construcción- y ayuda mutua -como modo de organización colectiva-, bajo la orientación Técnica del Ministerio de Obras Públicas, solución que fue de corta duración dada la irregularidad en la producción y el bajo rendimiento y calidad. Del tercio de viviendas de producción privada, la mitad corresponde a iniciativas de auto construcción en manos de la población, de bajo nivel técnico (foto 1).

Foto 1 - Viviendas auto construidas

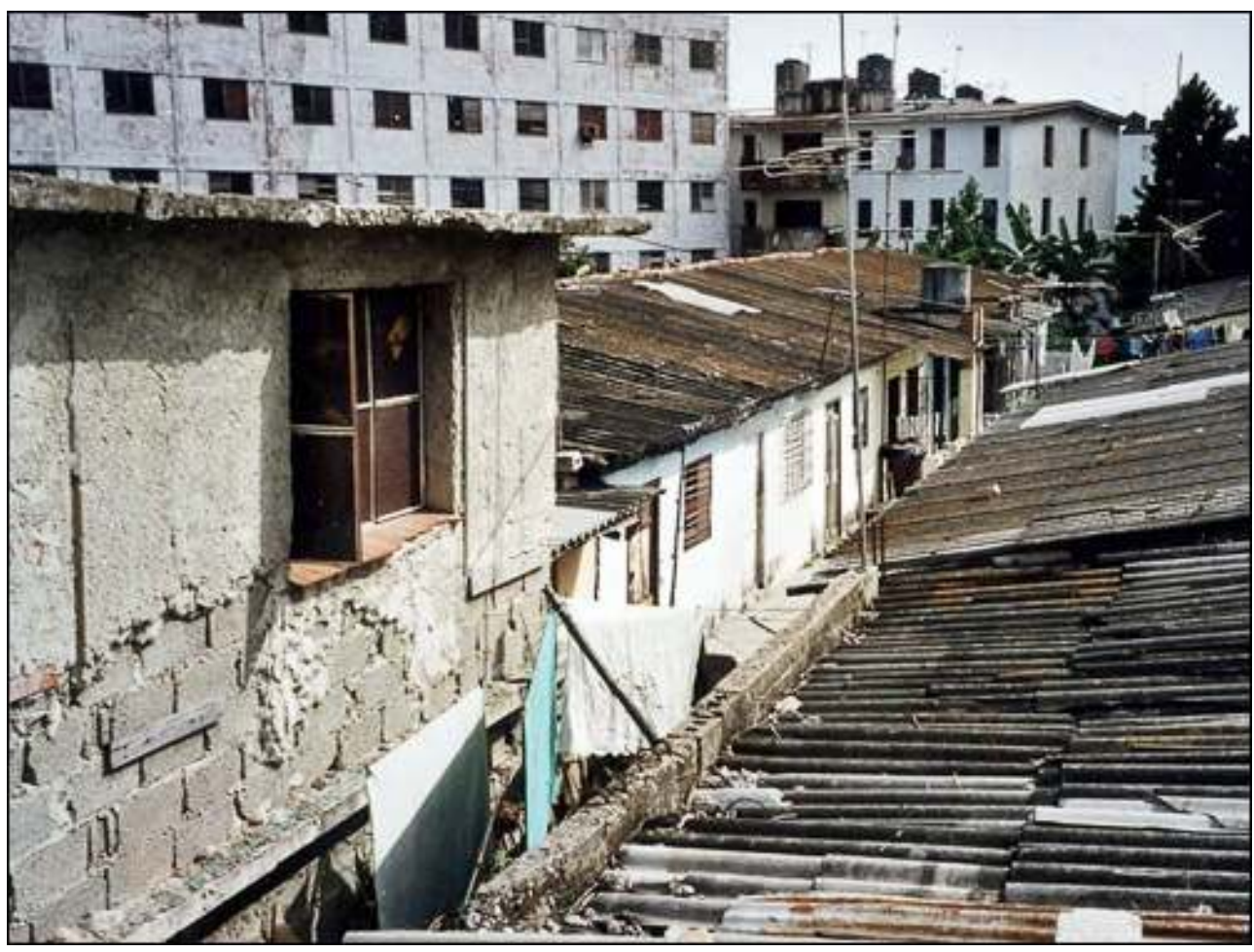

Fuente : Adriana Rabinovich

Subrayemos además que en este primer período se desarrollan modos de colaboración entre el INAV y el Colegio de Arquitectos, destinados a orientar el trabajo de estos últimos hacia la concepción y elaboración de modelos y soluciones técnicas y constructivas de vivienda popular urbana y rural. La búsqueda de valores arquitectónicos y urbanos por parte de los profesionales estuvo estrechamente vinculada con su adhesión al nuevo proyecto político, económico y social de la revolución. En términos de diseño, la preocupación por los aspectos estéticos, 
espaciales y funcionales se acompañó por lo tanto del dominio de los aspectos económicos, técnicos y de producción de proyectos de interés social.

\section{Centralización y sectorialización}

12 Un segundo período se inicia hacia 1965 con el desarrollo de la prefabricación, orientándose hacia 1970 a la industrialización pesada. En este marco, arquitectos y urbanistas elaboraron soluciones que ponían en relación "el proyecto" con los condicionamientos productivos y de montaje de las unidades de habitación basadas en las nuevas tecnologías. Sin duda, como señala Segre (1989 : 37), el VII Congreso de la UIA -el cual permitió difundir la experiencia cubana y establecer vínculos con profesionales de otros países preocupados por la problemática del hábitat popular- fue un "detonante teórico e ideológico" que buscó dilucidar los modos de lograr el equilibrio entre los valores estéticos y la necesaria masividad de objetos, edificios y ambientes requeridos por una sociedad socialista.

13 Al igual que en muchos países de diferentes latitudes, se propusieron modelos inspirados en el movimiento racionalista internacional en arquitectura y urbanismo asociados a la estética brutalista. Recordemos que el movimiento moderno, cuyos principios se encuentran desarrollados en los Congresos de Arquitectura Moderna (CIAM) y el Team X, dio lugar a modelos de hábitat social basados en criterios de racionalismo y funcionalismo, que propusieron "adaptar el hombre real al hombre tipo ideal”, el cual debería moldearse, adaptarse a los espacios producidos por la técnica. En Europa, este movimiento inspiró los grandes conjuntos habitacionales del período de entre guerras mientras que en América Latina, en las décadas de 1970 y 1980, se realizaron numerosos conjuntos habitacionales basados en los postulados del movimiento moderno pero con tintes nacionalistas. En Cuba, como destaca Mario Coyula (2006), los mismos se tradujeron en obras de gran calidad, como la Ciudad Universitaria José Antonio Echeverria, al mismo tiempo que "incubaron un fetichismo tecnocrático" de enfoque reduccionista, inadecuado para la resolución de problemas complejos como el de la vivienda ${ }^{4}$.

14 La calidad arquitectónica de los planes de vivienda que se extendieron por todo el país fue en efecto de corta duración. Se puso en marcha un proceso de producción centralizada en manos del Ministerio de la Construcción (MC) que absorbió entidades como el INAV y la DVC que habían desarrollado modelos con buena calidad de diseño y ejecución. En 1967 se disolvió el Colegio de Arquitectos sustituido en 1968 por el Centro Técnico Superior de la Construcción. A principios de los '70 se siguieron desarrollando proyectos innovadores en el marco de la Escuela de Arquitectura que sufrieron cambios en los procesos de construcción. El rol relevante de los arquitectos proyectistas se fue trasladando a los constructores e inversionistas. La innovación fue circunscribiéndose en áreas como la de conservación y restauración de monumentos históricos y la de construcciones escolares. (Coyula, 2006:6). En manos del MC la centralización se asoció en el ámbito de la vivienda a la sectorializacion tecnocrática, definiéndose dos líneas básicas de desarrollo.

La primera conservó la construcción artesanal pero aplicándola a edificios en bloques de cuatro plantas e incluyendo algunos elementos prefabricados simples como escaleras, vigas, fundaciones. Esta orientación normaliza, tipifica y estandardiza la 
vivienda en Cuba, dando lugar al modelo que dominara el paisaje urbano y rural en la isla (fotos 2 y 3 ).

Foto 2 - Construcción artesanal con elementos prefabricados

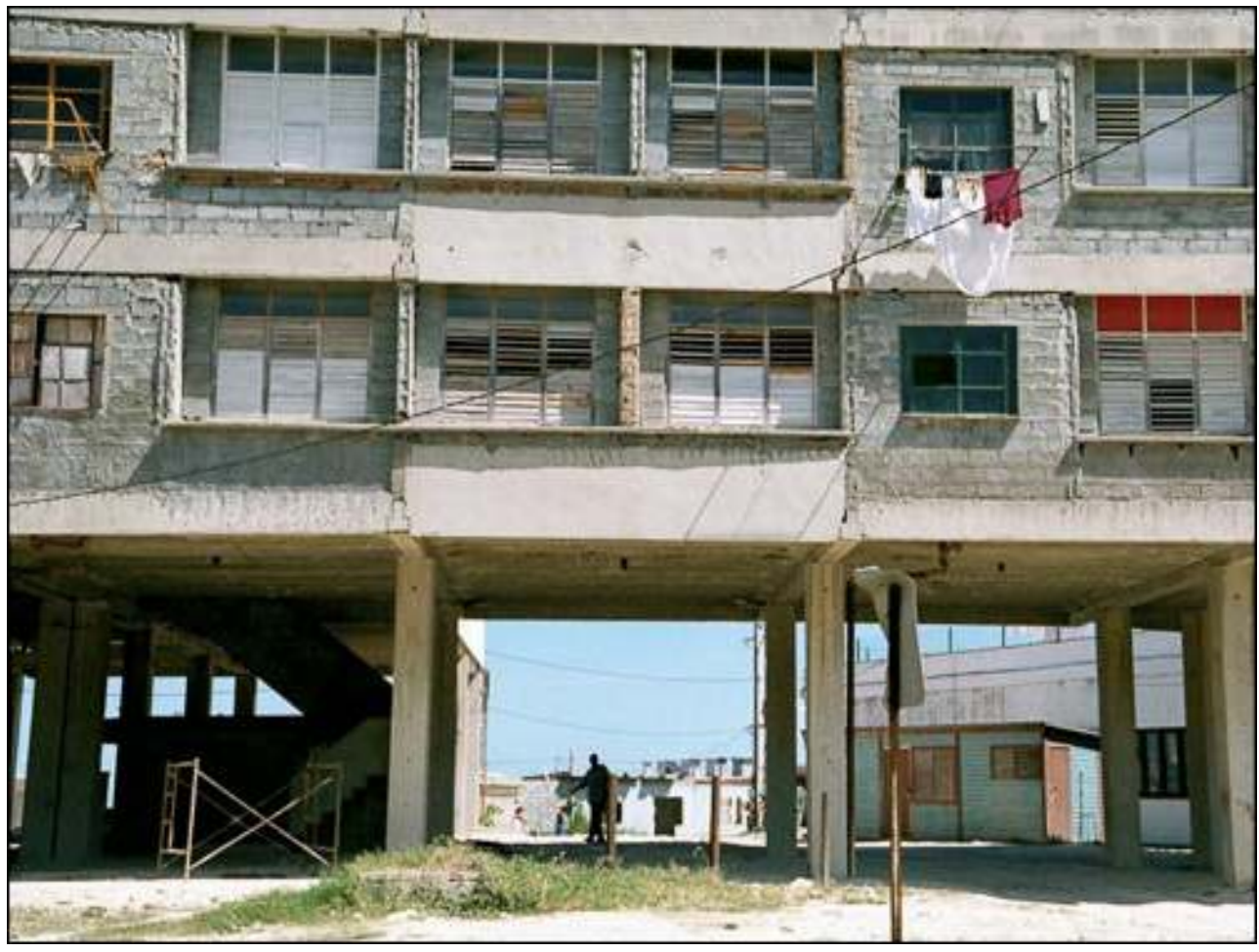

Fuente : Adriana Rabinovich 
Foto 3 - Construcción artesanal con elementos prefabricados

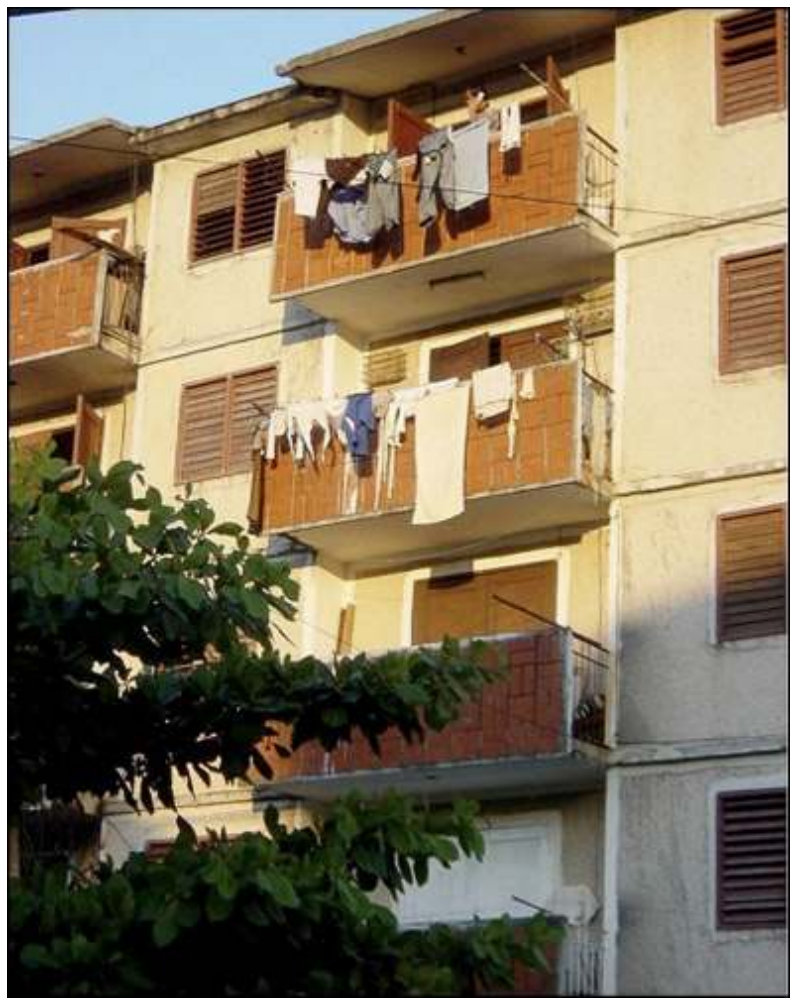

Fuente : Adriana Rabinovich

16 La segunda línea desarrollada por el MC en los '70 se caracterizó por la prefabricación pesada y la industrialización, asociada al crecimiento y consolidación del sector de la construcción -con un incremento del 46\% en 1971- y en particular de la industria de materiales y elementos de construcción. La producción de cemento por ejemplo pasó de 743 mil toneladas en 1958 a 13 millones 400 mil en el quinquenio 1975-1980, mientras que las plantas industriales de elementos prefabricados pasaron de 3 pequeñas antes de la revolución, a 93 en 1975 (Segre, 1989 : 179).

La consolidación de la base técnico material combinó la producción de elementos prefabricados con la experimentación de sistemas constructivos industrializados cerrados para producir edificios de viviendas en bloques (foto 4) y en altura (fotos 5, 6 y 7), inspirados inicialmente en el sistema europeo de grandes paneles surgido a partir de la segunda guerra (aligerados, con juntas simplificadas y cierta adaptación a las condiciones locales de producción a través de plantas a cielo abierto). Bien que la tendencia a la industrialización fue un eje común en la reconstrucción a partir de la segunda guerra en Europa, su fundamentación en Cuba como base de la producción de viviendas se apoya en las orientaciones del bloque socialista. El Congreso de Constructores de la URSS en 1954 dió lugar a la puesta en marcha de acelerados planes de prefabricación e industrialización que cambiaron los modelos de edificios, la organización y la producción de las viviendas, sustituyendo las tecnologías tradicionales artesanales por el sistema de grandes paneles de hormigón (Segre, 1988, Dandolova, 1996). Esta tecnología acentuó la monotonía y rigidez de las soluciones propuestas; los modelos de habitación se subordinaron a las técnicas de fabricación y a los modos de producción. 
Foto 4 - Bloque de viviendas con elementos prefabricados e industrializados

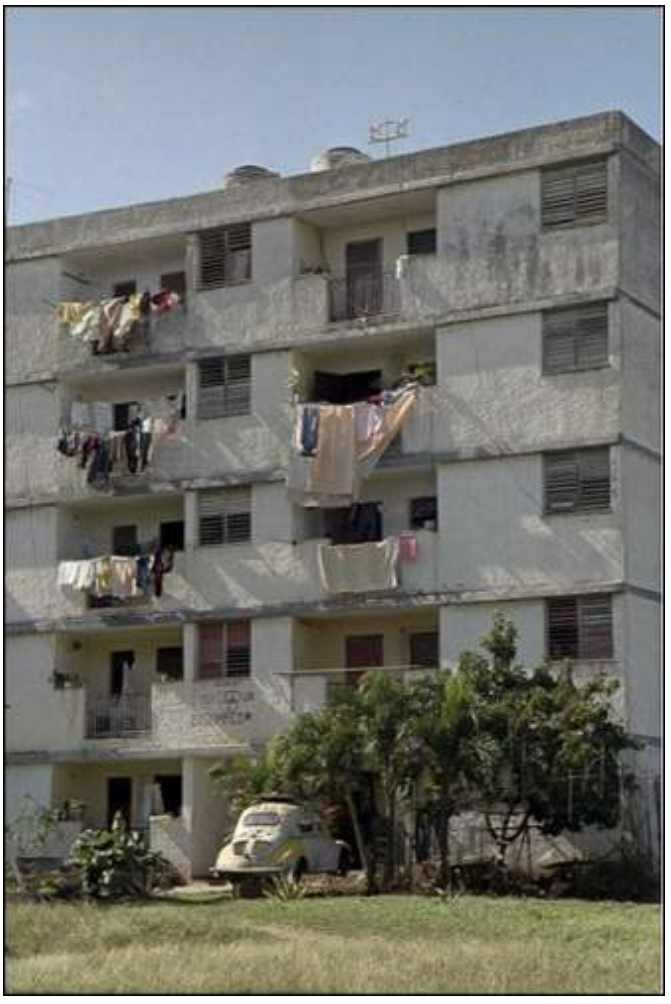

Fuente : Adriana Rabinovich

Foto 5 - Edificio en altura con elementos industrializados

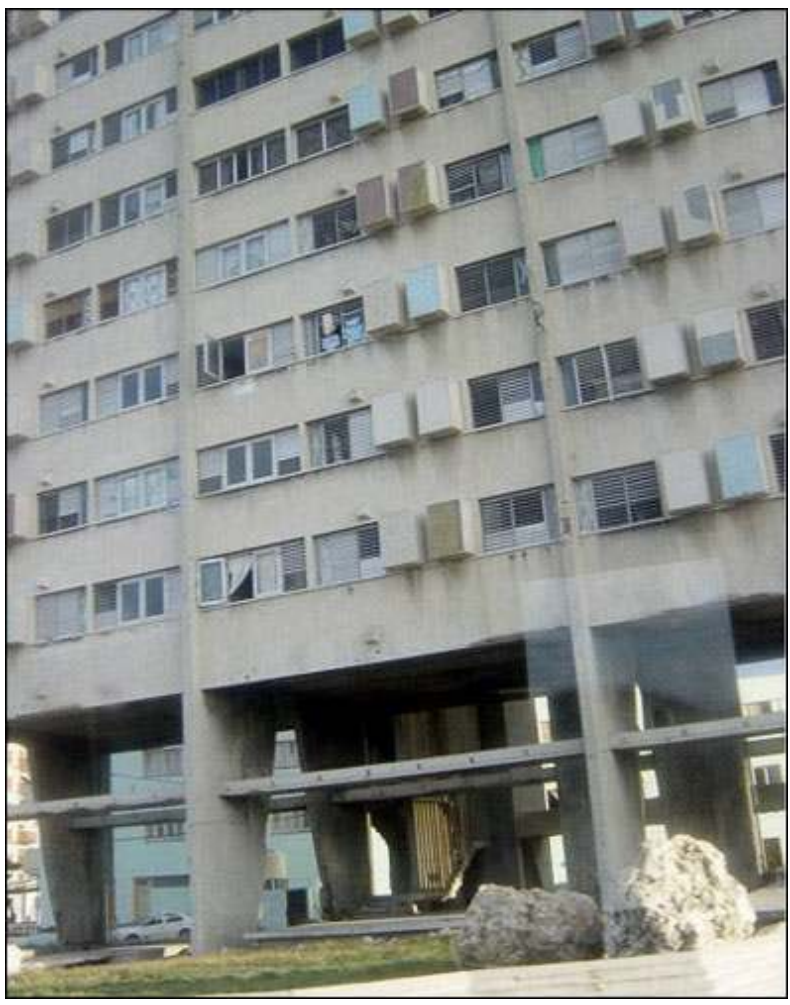

Fuente : Adriana Rabinovich 
Foto 6 - Edificio en altura con elementos industrializados

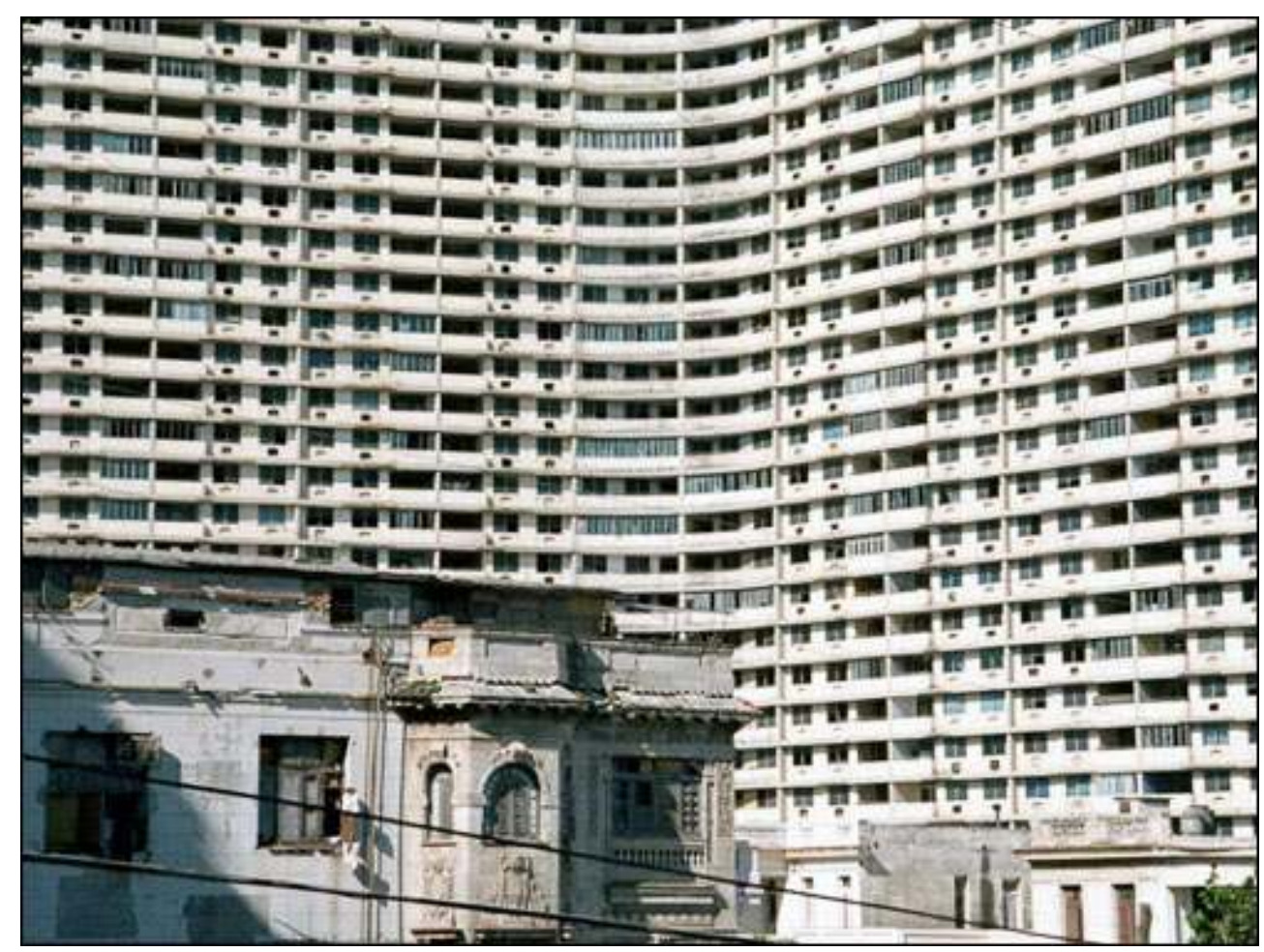

Fuente : LaSUR, EPFL

Foto 7 - Edificios en altura con elementos industrializados

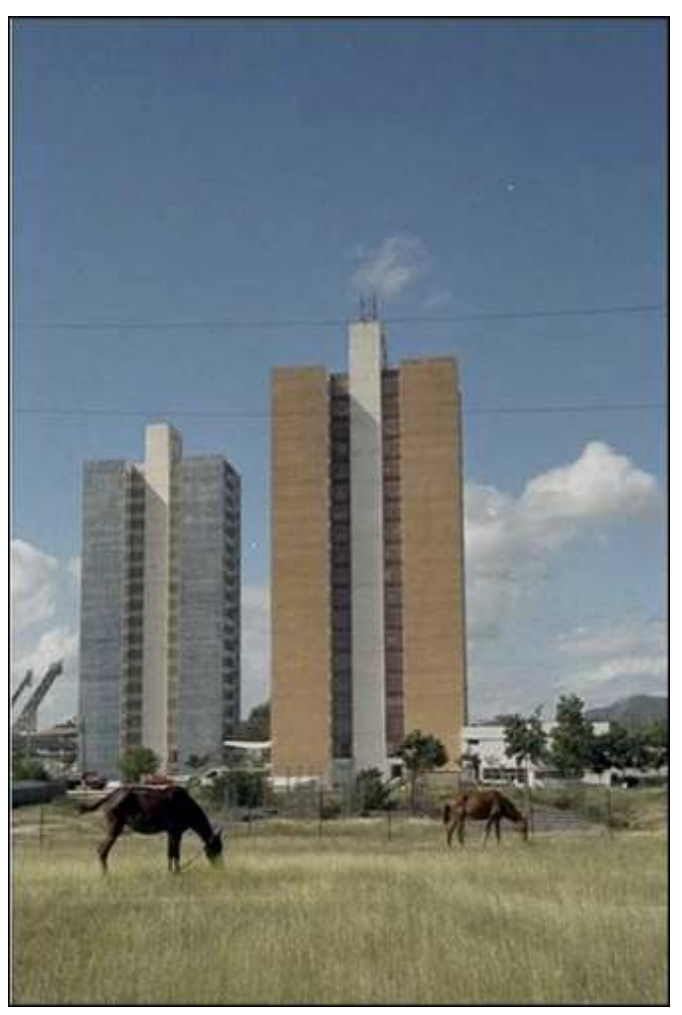

Fuente : Adriana Rabinovich 
Por parte de los proyectistas, la rigidez de los sistemas prefabricados e industrializados cerrados orientó, en la década de los ‘ 80 , la búsqueda de sistemas abiertos (en términos constructivos, productivos y de diseño) que permitieran combinar la prefabricación pesada con la construcción artesanal (fotos 8 y 9) y posibilitar respuestas tipológicas diversificadas en términos de superficie, organización espacial, expresión estética y articulación con la trama urbana.

Foto 8 - Bloque de viviendas con sistemas abiertos

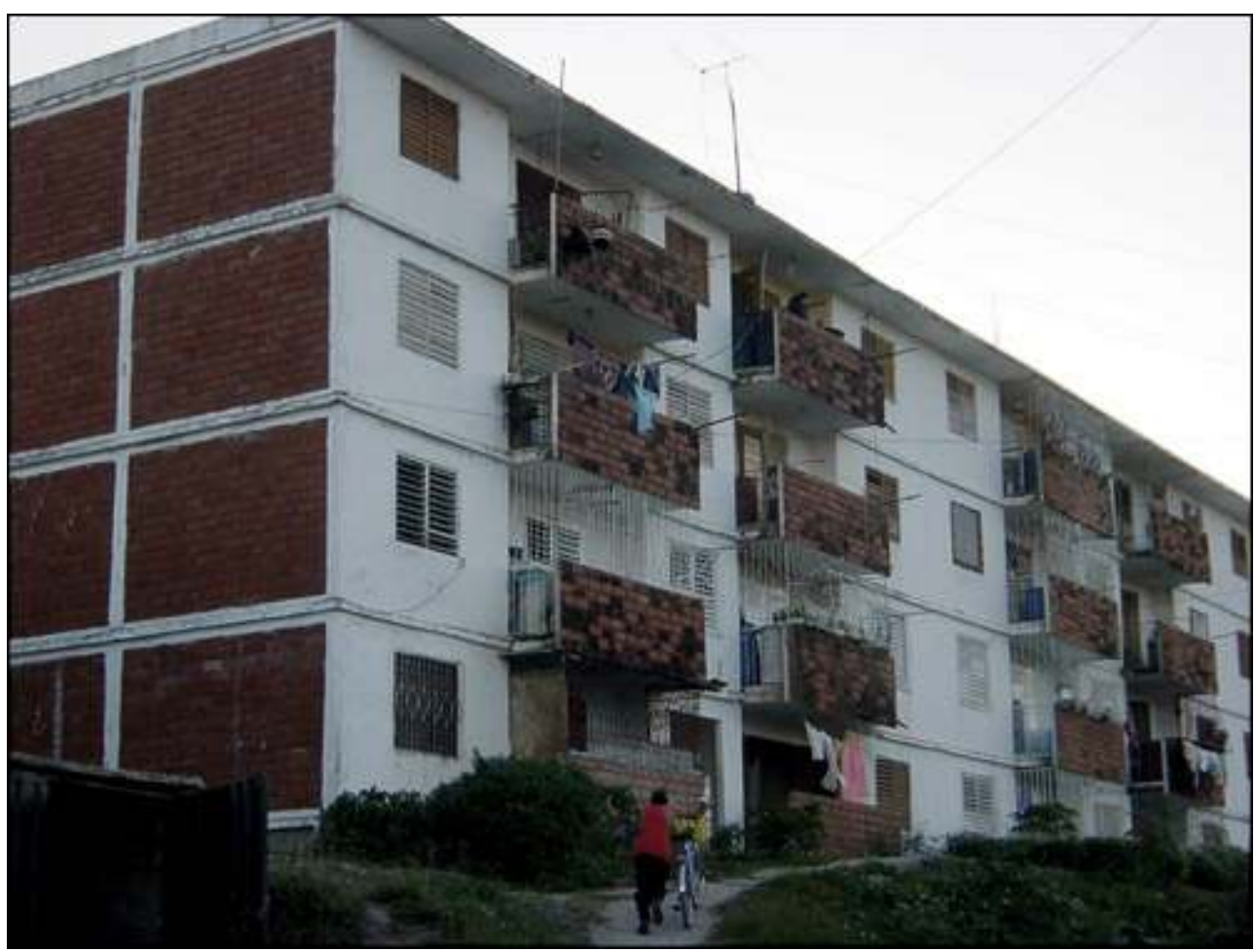

Fuente : Adriana Rabinovich 
Foto 9 - Bloque de viviendas con sistemas abiertos

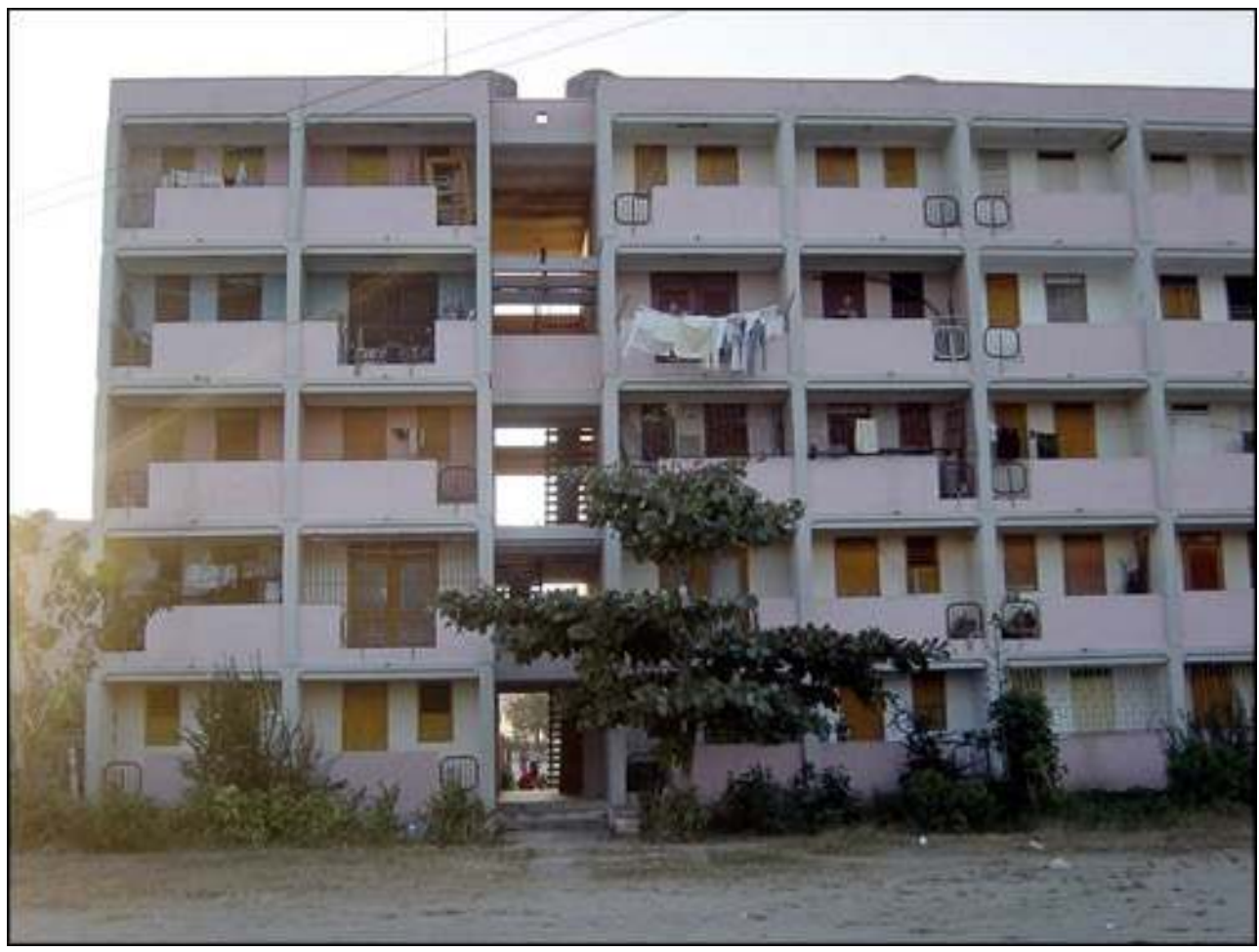

Fuente : Adriana Rabinovich

\section{Un modelo de producción colectiva}

Los censos de 1970 y 1981 demostraron que, mas allá de los planes de vivienda construidos por el estado, más de la mitad de las mismas fueron construidas o transformadas por los habitantes mismos, con poca asistencia técnica y disponibilidad de materiales (fotos $10 \mathrm{y} 11$ ). 
Foto 10 - Viviendas auto construidas

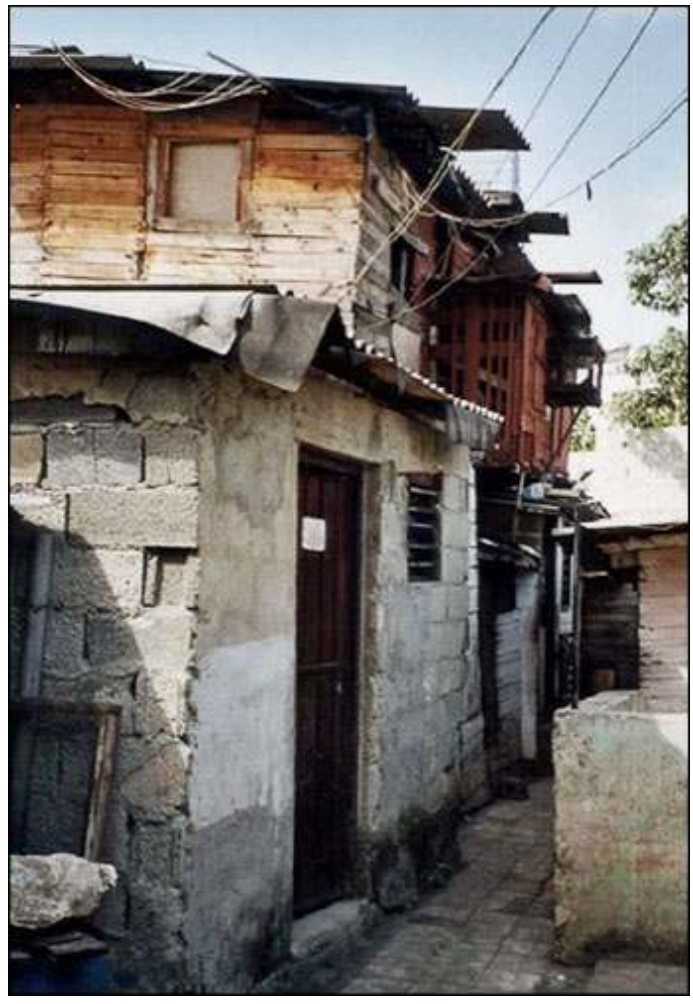

Fuente : Adriana Rabinovich

Foto 11 - Viviendas auto construidas

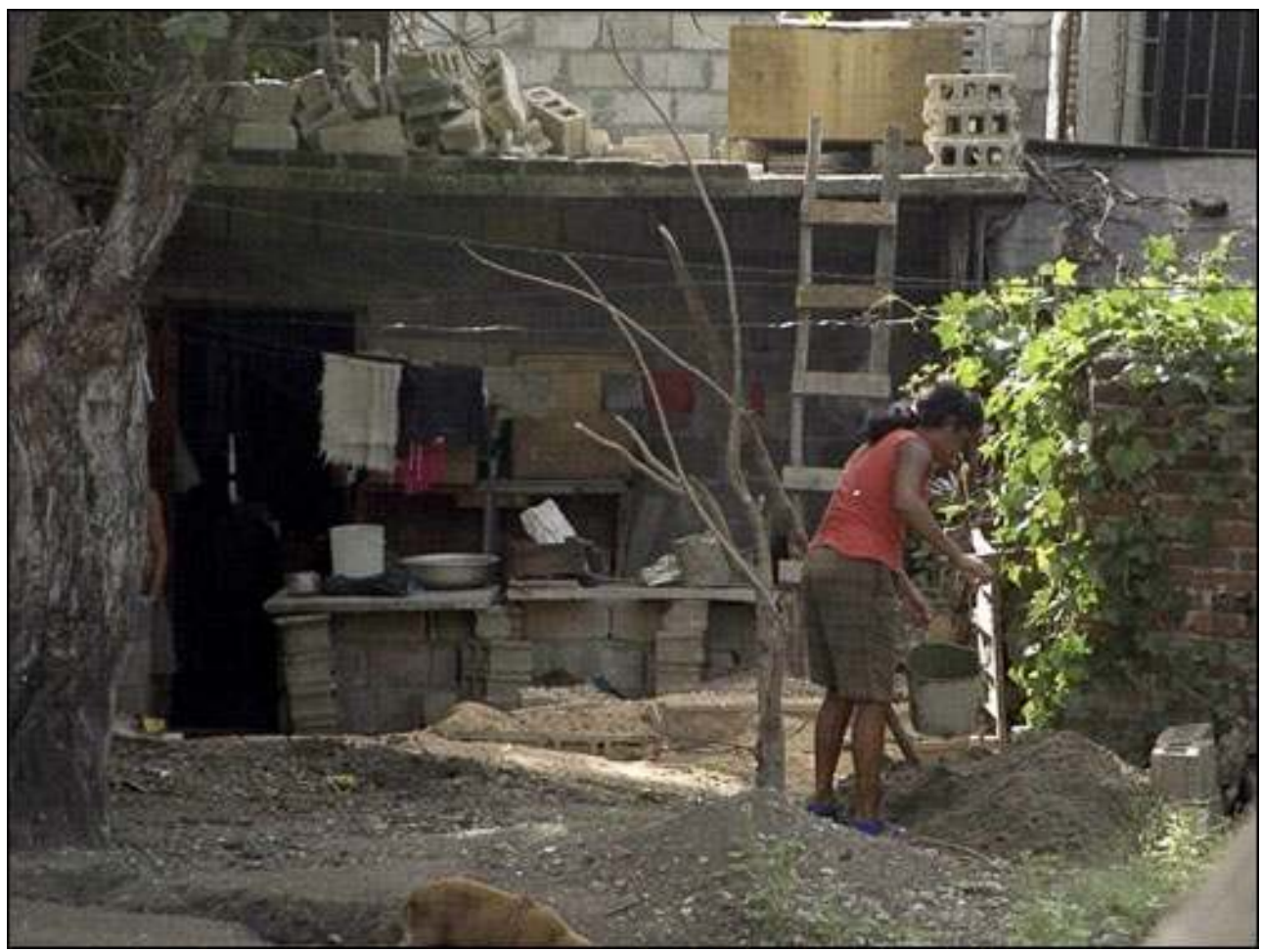

Fuente : LaSUR, EPFL. 

lado a un abordaje socio-político -en tanto representa una apertura del sistema político y del debate democrático- como también a una perspectiva de "puesta en proyecto" de procesos de producción colectiva que implican cuestiones de orden técnico de gran complejidad. Si desde hace mas de medio siglo, el primero nos remite a debates como los de participación "real vs. ideal”, participación vs. decisión, niveles de participación, participación voluntaria vs. forzada, instrumentalización de la participación (Arnstein 1969; Conan 1988, Atkinson, 1998, Bacqué, Sintomer, 1999, Callon, Lascoumes, Barthé, 2001, Blondiaux, 2001, Blondiaux et Sintomer, 2002, Bacqué, 2005, Lafaye, 2006), el proceso de proyecto nos permite entender en qué medida y a través de qué abordajes los saberes y las competencias de los habitantes pueden ser integrados y puestos en práctica en proyectos concretos (Conan 1988, 1989, Séchet 1989, Prost 1992, Rabinovich 1996, 2002, Romero, Mesías, 2004).

\section{La innovación en el periodo especial}

23 A pesar de los importantes planes y proyectos implementados durante más de medio siglo en el marco de las políticas revolucionarias, la vivienda siguió y sigue siendo un problema grave en Cuba.

Por un lado, las transformaciones en la estructura de la sociedad (crecimiento de la población joven, aumento de divorcios, aumento de la esperanza de vida, fuerte concentración de población en zonas urbanas) y la intensificación de las catástrofes naturales y por el otro, la inadecuación de ciertos aspectos de las políticas publicas (modelo único de prefabricación e industrialización; falta de políticas de mantenimiento y rehabilitación; falta de políticas de sostén a la auto construcción 
independiente) se han ido traduciendo en un aumento en las necesidades de rehabilitación de viviendas existentes y la construcción de viviendas nuevas.

En la década del 90 , la búsqueda de soluciones alternativas para enfrentar la problemática habitacional se vio precipitada por la caída del bloque socialista y la consecuente ruptura de los lazos de colaboración de los países del Este con Cuba. La misma trajo aparejada una profunda crisis comercial, productiva y financiera que afectó la base técnico material del sector de la construcción y desembocó en la paralización de la producción de materiales y de los programas de viviendas.

Para paliar esta situación, las reformas que acompañaron el llamado "Periodo especial en tiempos de paz" abrieron la vía a acciones colectivas alternativas surgidas al amparo de medidas excepcionales como: cierto grado descentralización del poder ejecutivo; diferentes márgenes de autonomía concedido a los actores no estatales; apertura a inversiones extranjeras (en particular a través de joint ventures); apertura a la cooperación internacional para el desarrollo; autorización del trabajo independiente a pequeña escala y crecimiento de la autonomía y el autofinanciamiento de las empresas estatales (Escaith, 1999).

Muchas de las alternativas implementadas pueden considerarse verdaderos nichos de innovación, tanto en el nivel institucional como en relación con las soluciones aportadas. En el marco de asociaciones sin fines de lucro, de organizaciones no gubernamentales y de otras estructuras y redes institucionales, prueba de un protagonismo creciente de nuevos modos de organización de la sociedad civil ${ }^{6}$ con diferentes grados de autonomía respecto del Estado, se diseñaron e implementaron respuestas alternativas que de-construyeron políticas y modelos de hábitat producidos "desde arriba" reconstruyéndolos "desde abajo" a través de nuevas prácticas.

Las ONGs en particular tuvieron un gran desarrollo entre 1992 y 1996, periodo en el cual intentaron construir, con mayor o menor éxito, nuevos modos de relación entre la sociedad y el estado. Cumpliendo los requerimientos del gobierno, las ONGs cubanas deben registrarse oficialmente, tener una institución gubernamental que las esponsoriza y sujetarse ellas mismas a disolución por el Ministerio de Justicia. Inspiradas y apoyadas por ONGs contrapartes europeas y canadienses, las ONGs cubanas - alrededor de 50 en dicho periodo- recibieron entre 1993 y $1996 \$ 42$ millones que canalizaron áreas como las energías alternativas, el desarrollo comunitario, el medioambiente, la educación popular, la promoción de la mujer y la construcción institucional. En 1994 habían registrados 108 proyectos en el marco de convenios con 66 ONGs extranjeras.

Sin embargo, pocas de ellas disponían de verdadera autonomía de decisión y progresivamente, criticaron el excesivo control de sus acciones por parte del Estado, reclamaron mayores grados de autonomía en la administración y coordinación de los proyectos y cuestionaron las restricciones impuestas para la creación de nuevas organizaciones. Y si bien en diferentes oportunidades, las ONGs declararon unánimemente no aceptar ni adherir a ningún proyecto que pudiera apoyar la política de los Estados Unidos contra Cuba y manifestaron su adhesión total al socialismo, el rol de las ONGs en el paisaje institucional cubano fue de corta duración. En 1996, el registro de nuevas ONGs fue congelado, los roles de muchas de las existentes considerablemente reducidos mientras que otras fueron directamente disueltas bajo la justificación oficial que sus acciones serian tomadas directamente en manos del estado (Dilla, 2006). 
30 Es el caso de Hábitat-Cuba, Sociedad para la Vivienda y el Urbanismo creada -y registrada legalmente en el Ministerio de Justicia en 1994- por profesionales de la construcción activos hasta el momento en diferentes organismos de Estado, quienes no adherían a la dicotomía establecida entre técnica y diseño -en términos de calidad espacial, funcional y estética- que caracterizaban los planes masivos de viviendas nuevas construidas, la falta de planes de rehabilitación y que al mismo tiempo cuestionaban la falta de contacto con la población para la formulación de los proyectos. Los profesionales implicados en Hábitat-Cuba diseñaron e implementaron estrategias alternativas de urbanismo participativo, en un contexto polarizado entre la construcción del Estado y de los particulares.

\section{Proyectos y programas de vivienda alternativos}

Los antecedentes de los proyectos participativos de vivienda colectiva realizados por Habitat-Cuba se encuentran en el programa del Arquitecto de la Comunidad (AC) a escala de la vivienda unifamiliar. En este programa, el trabajo directo con las familias se inspiraba en un método participativo (Livingston, 1995, 2002) basado en un abordaje global del proceso de concepción para proyectos de transformación, puesta en estado y construcción de viviendas individuales. Concebido desde un enfoque de metodología de proyecto en arquitectura, dicho "método" difiere de los abordajes participativos que transforman a los profesionales en simples asistentes técnicos como también de aquellos que confinan la implicación de los habitantes a la fase de construcción.

Dicho "método" concibe en efecto el "proyecto" como un proceso interactivo entre profesionales y habitantes que, en sus fases iniciales, esta destinado a definir el problema a resolver y no solamente a encontrar una solución a un problema dado. Sobre esta base, y gracias al aporte de disciplinas como la psicología, la sociología y el derecho, y a técnicas de trabajo simples, es posible tener en cuenta el carácter evolutivo de la demanda de los habitantes y trabajar con ellos para decodificar sus aspiraciones latentes (Rabinovich, 2002), lo que se traduce en una mayor adecuación del hábitat y engendra mayor satisfacción.

Cabe señalar que inicialmente se buscó integrar este abordaje de trabajo participativo en los organismos estatales existentes, particularmente a través de seminarios de capacitación impartidos a los profesionales de la construcción. A pesar del interés que "el método" suscitaba en muchos profesionales, era muy difícil vencer las inercias institucionales existentes y el programa no era implementado.

La innovación sólo fue posible en el marco de estructuras independientes desde el punto de vista operativo y económico y en 1994, a escala de la vivienda individual, el programa AC había dado lugar a 180'000 consultas familiares a lo largo de la isla. En 1996 el programa fue retenido entre las cuarenta "Prácticas ejemplares" por la ONU/ Habitat, gracias a su carácter innovador y su potencial de replicación en otras latitudes.

Fue en 1998, cuando los AC gozaban de un amplio reconocimiento nacional e internacional, que el programa fue integrado en el jirón del estado cubano. Su incorporación en el marco de las políticas publicas se consideró un éxito que permitiría ampliar y replicar los resultados del AC enriqueciendo a su vez los planes y programas sectoriales existentes. Sin embargo, el pasaje bajo la tutela del Instituto de la Vivienda no permitió garantizar las condiciones institucionales necesarias a la innovación, lo que ha tendido a desnaturalizar el programa y frenar su crecimiento ${ }^{7}$. De asesores de la 
población, los Arquitectos de la Comunidad se transformaron en inspectoresfuncionarios (Coyula, $2006: 20$ ).

Hábitat-Cuba redefinió así su estrategia institucional centrando su acción en operaciones de urbanismo participativo a escala de conjuntos habitacionales y viviendas colectivas siempre para los sectores desfavorecidos de la población ${ }^{8}$. Se constituyó una forma de organización flexible a través de una red descentralizada de oficinas multidisciplinarias autónomas implantadas en las principales ciudades del país -que ejecutaban proyectos y programas- y una oficina de coordinación nacional en La Habana, que ofrecía servicios de asistencia a las oficinas de la red. En el 2000, HábitatCuba contaba con 550 socios.

Siguiendo una lógica de investigación-acción-formación, las diferentes actividades se articulaban a través de cuatro departamentos: las prácticas demostrativas, la metodología, la comunicación y la formación. Las prácticas demostrativas eran verdaderos laboratorios de experimentación co-financiados por el estado cubano y la cooperación internacional y las viviendas se entregaban en propiedad a la población siguiendo el sistema de subvenciones de las políticas publicas en vigencia. Las intervenciones se organizaban en función de tres líneas principales : el trabajo con la población asociándola activamente en el proceso de concepción del hábitat, la promoción de soluciones económicamente adaptadas a la realidad cubana que no dependieran de fondos extranjeros y pudieran por lo tanto ser reproductibles -en particular gracias al desarrollo de tecnologías y materiales adaptados al contexto- y la implicación de los diferentes actores relacionados con la problemática del hábitat Estado, instituciones técnicas, habitantes y organismos de cooperación internacional para el desarrollo (García, 1997).

Un estudio comparativo entre un conjunto de viviendas de construcción estatal basado en la prefabricación pesada y dos ejemplos de prácticas demostrativas de Hábitat-Cuba en la ciudad de Holguín -un conjunto de viviendas nuevas y un proyecto de rehabilitación en el centro de la ciudad, (fotos 12 a 15)- puso en evidencia que las innovaciones introducidas por los equipos de Hábitat-Cuba permitieron obtener viviendas de calidad constructiva comparable a las producidas por el Estado, de mejor calidad espacial y diversidad funcional, a costos inferiores. Respecto de la autoconstrucción, se produjeron viviendas de mucha mejor calidad arquitectónica y constructiva con poco incremento en los costos. 
Foto 12 - Conjunto habitacional de viviendas nuevas construido bajo la direción de Hábitat-Cuba

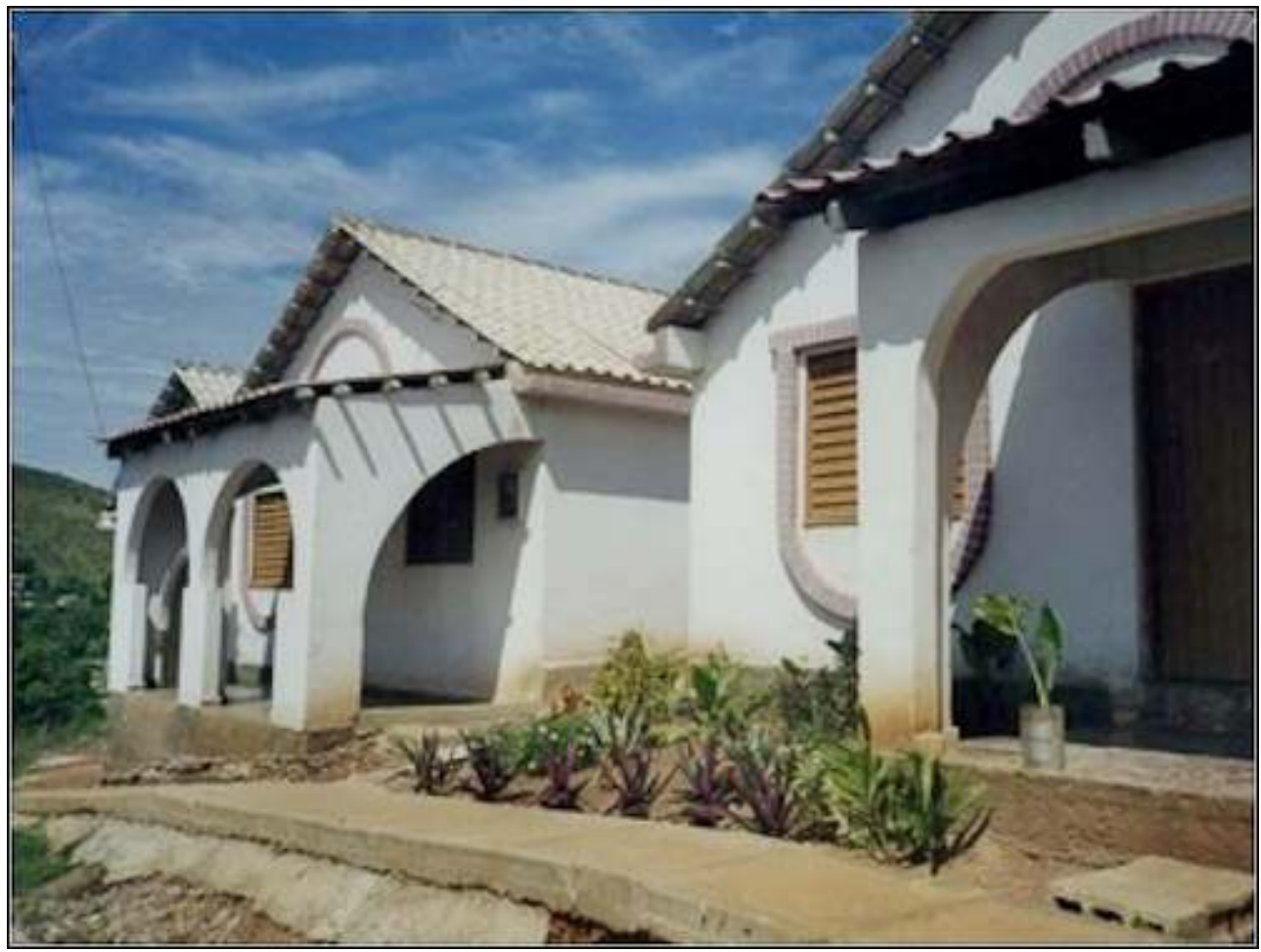

Fuente : Adriana Rabinovich

Foto 13 - Conjunto habitacional de viviendas nuevas construido bajo la dirección de Hábitat-Cuba

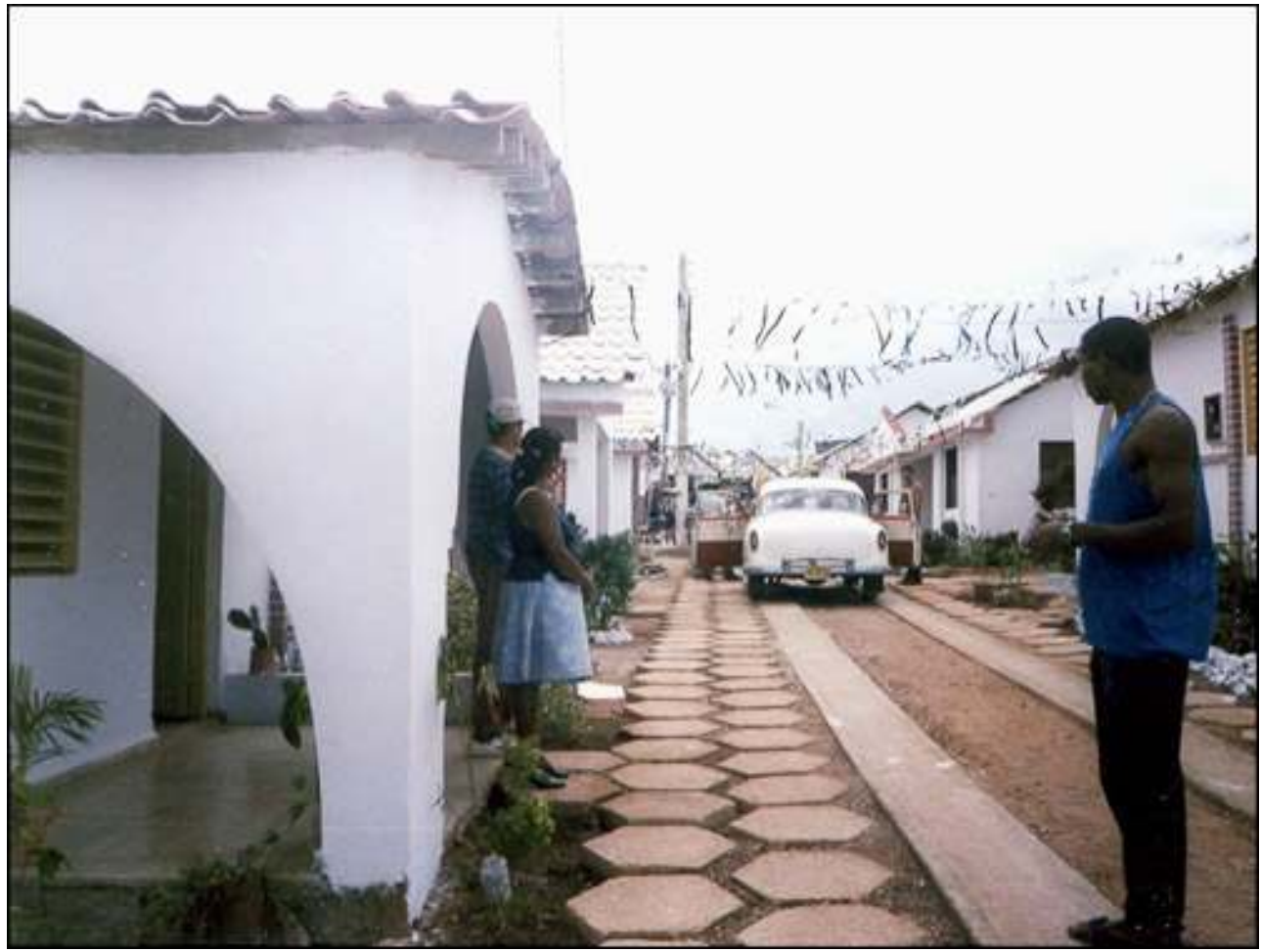

Fuente : Adriana Rabinovich 
Foto 14 - Concepcion participativa de proyecto de rehabilitación por Hábitat-Cuba

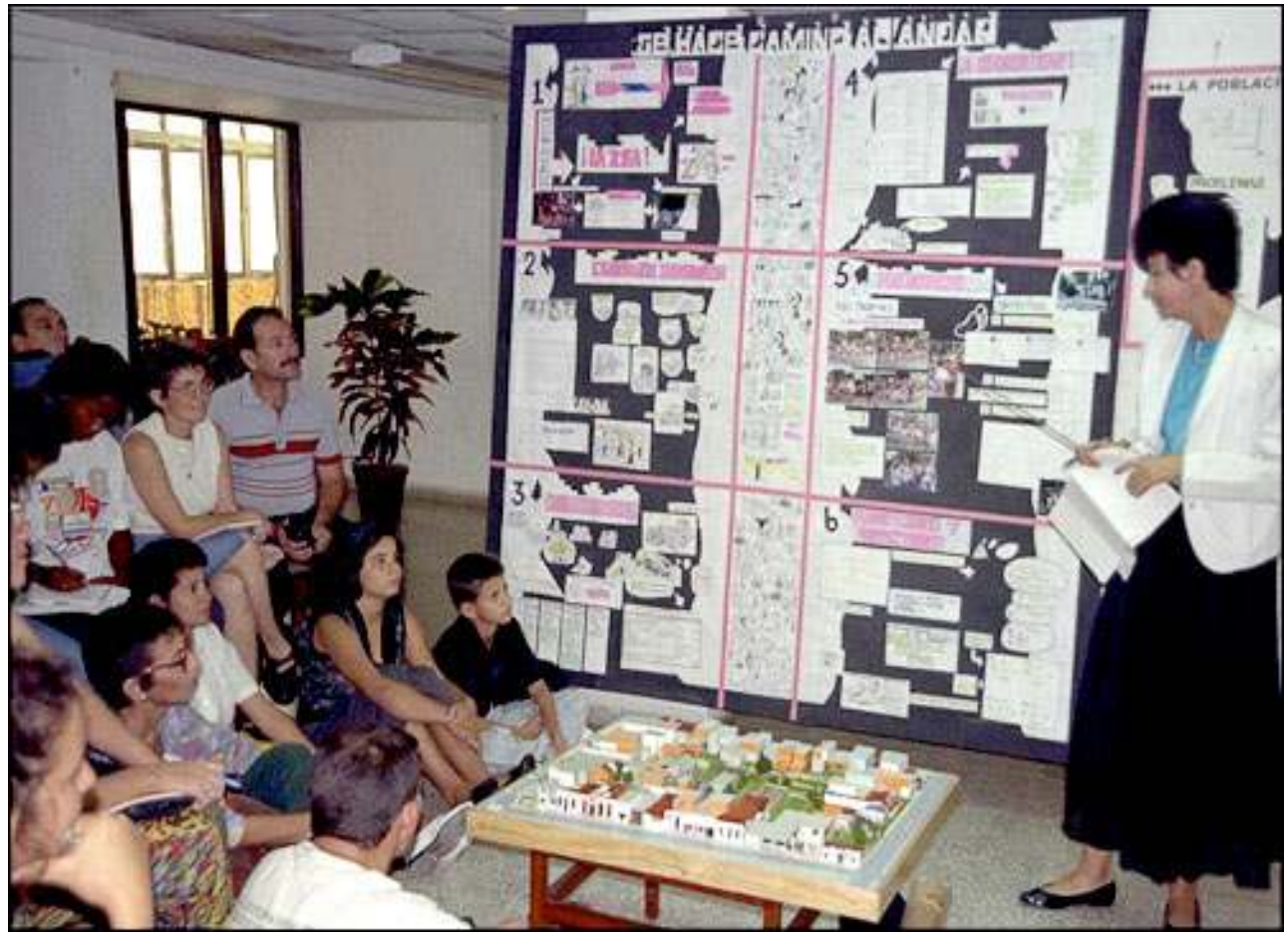

Fuente: LaSUR, EPFL.

Foto 15 - Proyecto de rehabilitación bajo la dirección de Hábitat-Cuba

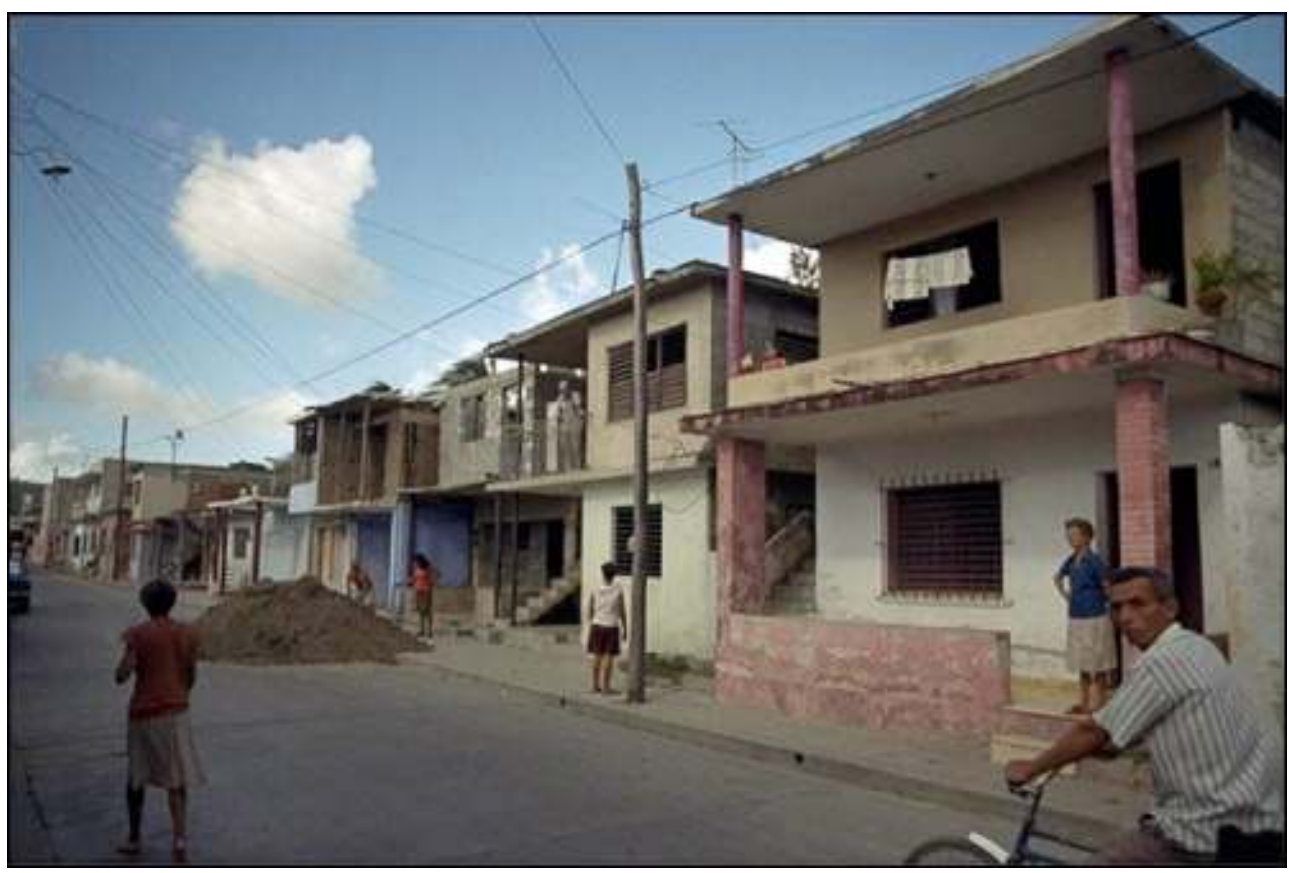

Fuente : Adriana Rabinovich

39 En la tabla 1 se comparan los costos de cada proyecto y en la tabla 2 se indica la repartición de los mismos entre los diferentes actores (García Pleyán, Pérez, 2002)ํ. 
Tabla 1 - Comparación de los costos de las viviendas en los barrios estudiados

\begin{tabular}{|l|l|l|}
\hline Costos de construcción de una vivienda & Pesos & USD \\
\hline Vivienda nueva estatal, Díaz Coello & 14000 & 7500 \\
\hline Vivienda autoconstruida (insalubres), Los Trenes & 3500 & - \\
\hline Vivienda nueva, Los Trenes & 14100 & 2000 \\
\hline \hline Vivienda autoconstruida, La Manzana, centro ciudad & 13800 & - \\
\hline \hline Vivienda nueva, La Manzana, centro ciudad & 16000 & 3500 \\
\hline \hline Vivienda rehabilitada, La Manzana, centro ciudad & 3200 & 1200 \\
\hline
\end{tabular}

Fuente : García Pleyán, Pérez, 2002

Tabla 2 - Costos asumidos por cada actor en los procesos de transformación estudiados

\begin{tabular}{|l|l|l|l|l|l|}
\hline & \multicolumn{2}{l|l}{ Estado } & Población & $\begin{array}{l}\text { Cooperación } \\
\text { internacional }\end{array}$ \\
\hline & Pesos & USD & Pesos & USD \\
\hline Vivienda nueva estatal, Díaz Coello & 9,764 & 7,500 & 4,184 & - \\
\hline $\begin{array}{l}\text { Vivienda autoconstruida (insalubres), Los } \\
\text { Trenes }\end{array}$ & - & - & 3,500 & - \\
\hline \hline Vivienda nueva, Los Trenes & 9,891 & - & 4,240 & 2,000 \\
\hline \hline Vivienda nueva, La Manzana, centro ciudad & - & - & 14,000 & - \\
\hline \hline $\begin{array}{l}\text { Vivienda rehabilitada, La Manzana, centro } \\
\text { ciudad }\end{array}$ & 9,543 & - & 6,457 & 3,500 \\
\hline Vivienda nueva estatal, Díaz Coello & 588 & - & 2,612 & 1,235 \\
\hline
\end{tabular}

Fuente : García Pleyán, Pérez, 2002

En ese sentido, las prácticas demostrativas de Hábitat-Cuba pusieron en evidencia el potencial de respuestas innovadoras en Cuba que intentan reconciliar los abordajes técnicos con los del diseño a través de procesos que incluyen nuevos modos de relación entre técnicos, profesionales y habitantes.

41 En el 2000 la acción de Hábitat-Cuba fue nuevamente distinguida a nivel internacional, seleccionada entre las cuarenta "Buenas Prácticas" retenidas por la ONU/Hábitat y sus acciones inspiraron otras organizaciones latinoamericanas. Más allá del potencial de innovación que significó la creación misma de esta ONG en el contexto cubano, la estrategia institucional y las experiencias realizadas enriquecieron los abordajes y las 
prácticas existentes en varios niveles. Por un lado, porque las acciones sobrepasaron los aspectos físicos de la vivienda para ampliarse a sus dimensiones económica, jurídica, social, medioambiental y política. Por otro lado por la importancia acordada por Hábitat-Cuba a la implicación de los diferentes grupos de actores basada en la necesidad de fundar la innovación en la concertación institucionalizada, particularmente con las organizaciones de masas, las de base y los poderes públicos, tal como lo había demostrado la experiencia del AC. En relación con la participación por lo tanto, las acciones de Hábitat-Cuba abrieron el debate tanto en sus dimensiones sociopolíticas como en relación con el proceso de proyecto.

A nivel nacional sin embargo, más allá del éxito obtenido en algunas provincias, la extensión del abordaje innovador se encontraba dificultado precisamente en el plano de construcción de alianzas interinstitucionales en diferentes niveles. Sin eludir un proceso de critica interna, los profesionales de Hábitat-Cuba buscaron comprender en qué medida sus acciones eran percibidas como "amenazantes" para otros organismos, en particular en relación con las prácticas centralizadas y sectoriales de vivienda.

Las líneas estratégicas elaboradas para enfrentar el desafío de sobrepasar estos obstáculos no tuvieron larga vida ya que en julio de 2001, por orden del gobierno central, Hábitat-Cuba fue disuelta con el pretexto oficial de que "las razones por la cuales la Sociedad había sido creada ya no existían". Si el problema de la vivienda sigue siendo crucial en Cuba, debemos inferir de esta decisión que el gobierno cubano consideró superado el Periodo Especial y por lo tanto toda acción, innovadora o no, debía circunscribirse nuevamente a la esfera de las organizaciones del Estado?

Las razones profundas son sin duda mas complejas. Recordemos que el objetivo de Hábitat-Cuba nunca fue el de substituirse al Estado para enfrentar la problemática de la vivienda sino constituirse en un interlocutor válido en la generación de soluciones reproductibles y durables. Sin embargo, es evidente que Hábitat-Cuba fue victima de su propio éxito en la medida en que sus intervenciones ponían en cuestión la políticas publicas de vivienda, tanto en términos de los modelos construidos como de los actores implicados en los procesos de diseño y de producción. Al mismo tiempo, al involucrar activamente a la población, Hábitat-Cuba estaba trabajando a nivel de la base, generando dinámicas alternativas a las de las organizaciones establecidas y reconocidas oficialmente. Paralelamente, su capacidad de captar recursos financieros tanto nacionales como extranjeros se iba acrecentando y sus modos de relación con el Estado se iban orientando hacia una mayor autonomía. En ese sentido, la trayectoria de la institución y el destino de sus programas relevantes ilustran los modos de relación de las ONGs con el estado cubano y sobre todo, los vaivenes en los márgenes de autonomía acordados a la sociedad civil cuando sus acciones ponen en cuestión las políticas publicas en vigencia (Dilla, Oxhorn, 1999, Rabinovich, 2007).

\section{Qué futuro para la innovación en Cuba?}

Por casi medio siglo, la política habitacional cubana se apoyo esencialmente en soluciones basadas en la tipificación y la standardización, a través de la prefabricación y de la industrialización pesadas. En el marco de planes y proyectos estatales, realizados sin contacto ni intercambio con la población, el enfoque tecnocrático priorizo la cantidad y definió la calidad a través de lo constructivo. Los debates relativos a cuestiones centradas en atributos estéticos, simbólicos y expresivos fueron 
considerados como extranjeros a los problemas "reales". La arquitectura y el urbanismo fueron paulatinamente relegados al plano de la reflexión, de la enseñanza y de la investigación.

Al mismo tiempo, iniciativas como las de esfuerzo propio y ayuda mutua y de las microbrigadas, que permitieron integrar a la población de manera organizada en los procesos de producción de la vivienda y constituyeron un aporte relevante en la ampliación del parque habitacional en términos cuantitativos, no se tradujeron en nuevos aportes técnicos o de diseño.

47 En cuanto a la producción efectiva de viviendas, es importante subrayar que durante el mismo periodo, casi la mitad de las mismas fueron mantenidas, transformadas, o construidas por los habitantes de manera individual, fuera de planes y proyectos oficiales por parte del Estado. Construidas con escasa o sin asistencia técnica, con gran dificultad de acceso a materiales - a través de ventas subsidiadas por el Estado o de formas de mercado "sumergido" o "informal"- muchas de ellas sin reconocimiento jurídico, dichas habitaciones presentan problemas de seguridad y de salubridad que pueden ser alarmantes.

48 Los intentos de "reconciliación" entre abordajes tecnocráticos y de diseño, como también del trabajo con la población estuvieron presentes a lo largo del periodo revolucionario. Las experiencias alternativas independientes de la década de los 90 que lograron concretar dichos objetivos pusieron en evidencia que la emergencia de la innovación se relaciona por un lado, con su carácter "periférico al poder" y por el otro, con la "suspensión" de ciertos estándares -reglamentarios, jurídicos, institucionales, metodológicos- como condición de éxito.

Así, paradójicamente, la fragilidad de dichas experiencias o de sus posibilidades de extensión y replicación se relaciona con el riesgo de poner en cuestión los poderes y políticas sectoriales en vigencia como también el de no poder asegurar la extensión de las suspensiones y derogaciones que les permitieron operar de manera concreta.

Para concluir cabe subrayar que a pesar de los logros realizados y de los esfuerzos materiales y humanos consentidos, el problema de la vivienda sigue siendo uno de los mas acuciantes en la isla. A principios del 2006 se puso en marcha un nuevo programa en el sector de la vivienda, destinado a garantizar la producción anual de 100'000 unidades de habitación (acciones de rehabilitación y de construcción nueva), una cifra nunca alcanzada anteriormente. El debate parece abierto en Cuba en el marco de diferentes organismos de Estado. Cabe esperar que la revisión de las políticas sectoriales y la capitalización de las experiencias innovadoras existentes permitirán abrir un nuevo camino para la producción y el acceso a la vivienda para la población cubana.

\section{BIBLIOGRAPHIE}

Arnstein, S., 1969. A Ladder of Citizen Participation, JAIP, vol. 35, № 4, July, p. 216-224. 
Atkinson, R., 1998. Les aléas de la participation des habitants à la gouvernance urbaine en Europe, Annales de la recherche urbaine, $\mathrm{n}^{\circ}$ 80-81, p. 75-83.

Bacqué, M.E., Sintomer, Y., 1999. L'espace public dans les quartiers populaires d'habitat social, in Neveu C. (dir.), Espace public et engagement politique, Paris, L'Harmattan.

Blondiaux, L., Sintomer, Y., 2002. L'impératif délibératif, Politix, 15, n 57, p. 17-36

Blondiaux, L., 2001. Démocratie locales et participation citoyenne: la promesse et le piège, Mouvements, $\mathrm{n}^{\circ} 18$, Paris, p. 44-51.

Bacqué, M.E., 2005. Dispositifs participatifs dans les quartiers populaires, héritage des mouvements sociaux ou néo-libéralisme, in Bacqué, M. E., Rey, H., Sintomer, Y. Gestion de proximité et démocratie participatives, Paris, La Découverte, p. 81-99.

Callon, M., Lascoumes, P., Barthé, 2001. Agir dans un monde incertain. Essai sur la démocratie technique, Paris, Seuil, $358 \mathrm{p}$.

Conan, M., 1988. Le souci et la bienveillance. Regards sur la participation des habitants à la conception de leur habitat, Paris, CSTB, Plan Construction et Architecture, coll. Recherches.

Conan, M., 1989. Méthode de conception pragmatique en architecture, Paris, CSTB, Plan Construction et Architecture, coll. Recherches, $114 \mathrm{p}$.

Coyula, M., 2006. El trinquenio amargo y la ciudad distópica: autopsia de una utopía. Conferencia en el Instituto Superior de Arte (La Habana), ciclo La política cultural de la Revolución: memoria y reflexión, organizado por el Centro Teórico-Cultural Criterios, 19 de marzo de 2007. http:// www.criterios.es

http://laventana.casa.cult.cu/modules.php?name=News\&file=article\&sid=3666

Coyula, M., 1997. Medioambiente urbano y participación popular en Cuba: contexto nacional, in Coyula et al. Quienes hacen ciudad?Ecuador, SIAP, p. 123-150.

Dandolova, I, 1998. Los desafíos de la participación. La reconversión creativa de los inmuebles de grandes conjuntos (Sofia), in Pedrazzini, Y., Bolay, J.- C., Bassand, M., Habitat creativo, elogio de los hacedores de ciudades, Uruguay, Trilce, p. 152-169). Versión francesa in: Habitat créatif, éloge des faiseurs de villes, Paris, FPH, 1996.

Diaz, S., Franco, X., 1996. El Hábitat popular en Cuba. Experiencias y Nuevos Desafíos. Cuba, HabitatCuba.

Diaz, S., Garcia Pleyán, C., 2001. Hábitat-Cuba: Retos y prioridades de una experiencia cubana participativa, in Bolivar T. (dir.), Voces solidarias: Contribución a la participación para el diseño. Caracas, FAU-UCV/Consejo Nacional de la Vivienda, Misereor.

Dilla, H., 2006. Cuban Civil Society: Future Directions and Challenges. NACLA Report on the Americas, vol. 39, $\mathrm{n}^{\circ} 4$, p. 37-43.

Dilla, H., Oxhorn, P., 1999. Virtudes e infortunios de la sociedad civil en Cuba, Revista Mexicana de Sociologia, vol. 61, n 4, 10-12, Mexico, IIS-UNAM, p. 129-148.

Dufaux, F., Fourcaut, A, Skoutelsky, R., 2003. Faire l'histoire des grands ensembles. Bibliographie 1950-1980. Lyon, ENS, 208 p.

Escaith, H., 1999. Cuba pendant la "Période spéciale": ajustement ou transition. Cahiers des Amériques Latine, Dossier Cuba si, Cuba no? n³1/32, p. 55-82. Paris, Ideal.

García, U., 1999, Project Management by the Cuban NOG Habitat-Cuba, society for housing and planning, www.lth.se/fileadmin/hdm/alumni/papers/icm1999/icm1999-07.pdf 
García Pleyan, C. Perez, A. 2002. Evaluación comparativa de estrategias innovadoras de rehabilitación urbana en Cuba, in, Bolay, J.-C., Pedrazzini, Y., Rabinovich, A., (eds.), Innovaciones tecnológicas, medioambiente urbano y disparidades sociales en América Latina. Estudios de caso en Argentina, Bolivia y Cuba. Lausanne, EPFL, Cahiers du LaSUR n ${ }^{\circ}$, avril, p. 93-132.

Garcilazo de la Vega, M., 2001. Programa Arquitecto de la Comunidad, in Bolivar, T. (dir.), Voces solidarias, contribución a la participación para el diseño, Caracas, FAU/UCV \& Consejo nacional de la vivienda.

Lafaye, C., 2006. La démocratie participative est-elle soluble dans la gouvernance urbaine?, Territoires, Paris

Livingston, R., 1995. El método. Buenos Aires, De la Urraca.

Livingston, R., 2002. Arquitectos de la comunidad, El Método. Buenos Aires, CP67, 320 p.

Prost, R., 1992. Conception architecturale : une investigation méthodologique, Paris, L'Harmattan.

Rabinovich, A., 2007. Cuba, Best Practices : quel potentiel d'élargissement. Espaces et Sociétés, Villes et best practices, vol. 4, p. 85-100. Paris.

Rabinovich, A., 2002. De la participation à l'interaction : l'évolution d'un mythe, in Dansereau, F., Navez-Bouchanine, F. (eds.). Gestion du développement urbain et stratégies résidentielles des habitants. Paris, L'Harmattan, p. 213-236.

Rabinovich, A., 1996. Participation et architecture, mythes et réalités. Quelques cas d'habitats groupés en Suisse, Lausanne, Ecole Polytechnique Fédérale. Thèse de doctorat n 1514.

Reaud, B., 2006. Examining Cuban Civil Society, in Font, M. (ed.). Cuba: In Transition? Pathways to Renewal, Long-Term Development and Global Reintegration. Conference proceedings. New York, Bildner Center for Western Hemisphere Studies, Graduate Center, p. 231-246.

Séchet, P., 1989. La conduite des processus de conception de l'habitat, Paris, CSTB, Plan Construction et Architecture, coll. Expérimentations.

Segre, R., 1999. América Latina fin de milenio. Raíces y perspectivas de su arquitectura. La Habana, Arte y Literatura, 329 p.

Segre, R., 1989. Arquitectura y urbanismo de la revolución cubana. La Habana, Pueblo y Educación, $254 \mathrm{p}$.

Segre, R., 1988. Arquitectura y urbanismo modernos. Capitalismo y socialismo. La Habana, Editorial Arte y Literatura, $531 \mathrm{p}$.

\section{NOTES}

1. Esta contribución se nutre de investigaciones y asesorías llevadas a cabo por la autora entre 1996 y 2009 con contrapartes cubanas. Desde 2001, los estudios se inscriben en el Centro Nacional de Competencia en Investigación Norte-Sur (NCCR N-S), financiado por el Fondo Nacional Suizo para la Investigación Científica (FNSNF) y la Cooperación Suiza para el Desarrollo (COSUDE).

2. Declaración de Fidel Castro en el VII Congreso de la Unión Internacional de Arquitectos (UIA) celebrado en La Habana en 1963.

3. Como por ejemplo la Ley 26 que suspende la expulsión de los inquilinos por falta de pago del alquiler; la Ley 135 que rebaja los alquileres hasta de un 50\%; la Ley 218 sobre venta forzosa de solares no construidos; o la Ley 691 que fija un precio único al suelo urbano para evitar la especulación. Más tarde, la Ley de reforma urbana, una de las primeras en su estilo en América 
Latina tendiente a eliminar el valor de mercado de la vivienda integra y perfecciona las leyes anteriores y limita el monto máximo del alquiler de la vivienda al 10\% del ingreso familiar. En 1985, la Ley General de la Vivienda convertirá en propietarios al 85\% de la población cubana.

4. Son numerosas las críticas y evaluaciones de los grandes conjuntos habitacionales, ver entre otros: Dandolova 1996; Rabinovich 1996; Segre, 1999; Dufaux, Fourcaut, Skoutelsky, 2003.

5. Las microbrigadas permitieron reorientar hacia el sector de la construcción cerca de 40'000 de trabajadores que en los años '60 fueron absorbidos por la expansión agrícola, industrial y de servicios (Segre, 1989: 187). La Ley General de la Vivienda establece las modalidades de constitución y funcionamiento de las microbrigadas http://www.cubanet.org/ref/dis/ vivienda_2.htm

6. En Cuba existen diferentes modos de organización de la sociedad civil, como por ejemplo las tradicionales organizaciones de masa, reconocidas oficialmente como el corazón de la sociedad civil socialista, las cuales actúan como correas de transmisión "de abajo hacia arriba" en relación con el Estado. Entre 1990 y 1995 la crisis del periodo especial acentuó la tendencia a la búsqueda de autonomía de diferentes organizaciones y promovió la creación de otras nuevas como grupos de iglesias y asambleas religiosas, organizaciones sociales de base; organizaciones comunitarias; ONGs, sectores artísticos e intelectuales; actores de mercado, la oposición organizada, la comunidad de expatriados (Dilla, 1999, 2006). Mas allá de las diferentes definiciones de la sociedad civil, los expertos subrayan la necesidad de entender que la sociedad civil en el contexto cubano está separada del estado y es al mismo tiempo parte del mismo, ocupando espacios nacionales, internacionales e híbridos (Reaud, 2006).

7. Para un análisis de la evolución del programa Arquitectos de la Comunidad y de la posterior trayectoria de Hábitat-Cuba ver Rabinovich (2007) del cual se inspiran las reflexiones incluidas en este apartado.

8. Los actores cubanos afirman que en Cuba como resultado de las políticas habitacionales de la revolución las poblaciones desfavorecidas en materia de vivienda no constituyen necesariamente grupos marginales en términos de acceso a los procesos y medios de producción, a los servicios sociales o a los mecanismos de participación política. Sin embargo, las reformas puesta en marcha durante el Periodo Especial desestabilizaron el pretendido "equilibrio" anterior.

9. Para una explicación detallada del cálculo de los costos en relación con las distintas monedas ver (García Pleyán, Pérez, 2002).

\section{RÉSUMÉS}

Dans les premières années qui ont suivi la révolution cubaine, l'Etat embrassa la responsabilité totale dans le domaine du logement social. Cette contribution analyse les modalités de prise en compte des tensions entre critères technocratiques et ceux du "design " ainsi que le rôle attribué à la population dans les politiques et programmes d'habitations collectives depuis 1959 . Elle met en lumière le modèle étatique sectoriel lequel a progressivement priorisé la quantité et défini la qualité par des critères de productivité à bas coûts. L'exemple de l'ONG Habitat-Cuba illustre également la fragilité des expériences innovantes des années 1990 qui ont tenté de réconcilier les aspects technocratiques avec les attributs esthétiques, spatiaux et fonctionnels de l'habitat par des approches dites participatives. 
In the first few years following the Cuban revolution, the State assumed full responsibility for public housing. The present contribution analyzes modalities for dealing with the tensions between technological and design-related criteria, as well as the role set aside for the public in collective housing policies and programmes since 1949. It sheds light on the statist model that has gradually given priority to quantity while defining quality via criteria for low-cost productivity. The example of the NGO Habitat-Cuba also illustrates the fragile nature of the innovative experiments of the 1990s, which attempted to reconcile technocratic aspects with the aesthetic, spatial and functional attributes of housing by means of so-called participatory approaches.

INDEX

Keywords : Habitat Cuba, NGO, public policies, social housing, stakeholders

Mots-clés : Habitat Cuba, logement social, ONG, participation, politiques publiques

\section{AUTEUR}

\section{ADRIANA RABINOVICH}

Adriana Rabinovich, Centre National de Compétence en Recherche Nord-Sud, Université de Berne, Suisse. adriana.rabinovich@nstools.com 